\title{
PENERAPAN MEDIA JEJARING SOSIAL EDMODO UNTUK MENINGKATKAN HASIL BELAJAR FISIKA DASAR
}

\author{
Siwi Puji Astuti \\ Program Studi Informatika, Universitas Indraprasta PGRI \\ Email: siwiunindra2012@gmail.com
}

\begin{abstract}
Abstrak
Pola pembelajaran di perguruan tinggi yang terpusat pada dosen (Teaching Centered Learning) dinilai sudah tidak memadai lagi, dan harus diubah menjadi berpusat pada mahasiswa. Belakangan ini banyak tersedia media jejaring sosial yang mudah diakses secara mudah seperti facebook, twitter, line, instagram, edmodo, dan lain-lain. Media jejaring sosial dapat juga dimanfaatkan untuk keperluan pendidikan. Media jejaring sosial yang akan digunakan dalam keperluan penelitian ini adalah Edmodo. Penelitian ini dilakukan untuk mengetahui pengaruh positif penerapan media jejaring sosial edmodo terhadap hasil belajar fisika dasar. Penelitian ini dilaksanakan di Universitas Indraprasta PGRI pada mahasiswa tingkat pertama tahun akademik 2018/2019. Peneliti menggunakan metode penelitian kuantitatif. Desain eksperimen yang digunakan adalah classical experimental design. Adapun teknik analisis data yang digunakan adalah Independent sample t-test dengan menggunakan program SPSS 18. Hipotesis penelitian yang akan diuji yaitu ada pengaruh positif penerapan media jejaring sosial edmodo terhadap hasil belajar fisika dasar. Hasil perhitungan dari penelitian ini memiliki nilai sig 0,00 $<0,05$ yang menyatakan adanya pengaruh positif penerapan media jejaring sosial edmodo terhadap hasil belajar fisika dasar. Oleh karena itu hasil penelitian menyatakan bahwa terdapat pengaruh positif penerapan media jejaring sosial edmodo terhadap hasil belajar fisika dasar.
\end{abstract}

Kata kunci: Edmodo, Hasil Belajar Fisika Dasar

\begin{abstract}
The teacher-centered learning in universities has been no longer inadequate and must be changed to the student-centered learning. There have been lately many easily accessible social media such as Facebook, Twitter, line, Instagram, Edmodo, and others. Those media can be used for educational purposes. The social media to be used in this research is Edmodo. The research is carried out to know the positive effect of the application of Edmodo social media on the results of basic physics learning. The research is conducted on first-year students of the 2018/2019 academic year at Universitas Indraprasta PGRI. The researcher uses a quantitative research method and a classical experimental design. The data analysis technique used is the Independent sample t-test using the SPSS 18. The research hypothesis to be tested is there is a positive effect on the application of Edmodo social media on the results of basic physics learning. The calculation results of the research have a sig value of $0.00<0.05$, indicating that there is a positive effect of the application of Edmodo social media on the results of basic physics learning. In conclusion, the results of the research show that there is a positive effect of the application of Edmodo social media on the results of basic physics learning.
\end{abstract}

Keywords: Edmodo, Results of Basic Physics Learning

\section{PENDAHULUAN}

Berdasarkan UU RI No 12 tahun 2012 tentang pendidikan tinggi, pasal 1(2): "Pendidikan tinggi adalah jenjang pendidikan setelah pendidikan menengah yang mencakup diploma, program sarjana, program magister, program doktor, program profesi, serta program spesialis, yang diselenggarakan oleh perguruan tinggi berdasarkan kebudayaan bangsa
Indonesia." Pendidikan tinggi di Indonesia ada beberapa jenis diantaranya adalah Universitas, Institut, Akademi, dan Sekolah Tinggi. Perguruan tinggi juga ada yang berstatus negeri dan swasta. Pendidikan di tingkat perguruan tinggi sangat berpengaruh pada perkembangan bangsa dan negara. 
Salah satu Universitas swasta yang sedang berkembang di Jakarta adalah Universitas Indraprasta PGRI. Di UNINDRA terdapat empat fakultas yaitu, FMIPA, FTIK, FBS, dan FIPPS. Masing-masing fakultas menaungi 3 program studi. FMIPA terdapat program studi Pendidikan Fisika, Pendidikan Biologi, dan Pendidikan Matematika. FTIK terdapat program studi Teknik Industri, Arsitek, dan Informatika. FBS terdapat program studi DKV, Pendidikan Bahasa Indonesia, dan Pendidikan Bahasa Inggris. FIPPS terdapat program studi Pendidikan Ekonomi, Pendidikan Sejarah, dan Bimbingan Konseling. Pada Fakultas TIK (FTIK) terdapat beberapa program studi dengan beberapa jenis mata kuliah. Fisika Dasar merupakan salah satu mata kuliah dasar umum yang terdapat pada fakultas FTIK. Fisika Dasar ditujukan untuk mengenalkan konsep dasar fisika di tingkat sarjana teknik dan ilmu komputer.

Akan tetapi sebagai mata kuliah dasar umum, mata kuliah fisika dasar dianggap sebagai mata kuliah yang kurang menarik dan menakutkan bagi mahasiswa. Terkadang mahasiswa juga enggan untuk serius mempelajari mata kuliah ini yang dianggap tidak ada hubungannya dengan jurusan yang mereka pilih. Karena alasanalasan itulah dosen harus mencari cara agar tujuan pembelajaran fisika dasar dapat tercapai. Dimana pola pembelajaran di perguruan tinggi yang terpusat pada dosen (Teaching Centered Learning) dinilai sudah tidak memadai lagi, dan harus diubah menjadi berpusat pada mahasiswa (Student Centered Learning) [1].

Di sisi lain, teknologi informasi sudah sangat berkembang dan sangat terjangkau oleh semua kalangan termasuk dosen dan mahasiswa. Hal ini memungkinkan untuk memanfaatkan teknologi informasi sebagai media pembelajaran. Belakangan ini banyak tersedia media jejaring sosial yang mudah diakses secara mudah seperti facebook, twitter, line, instagram, edmodo, dan lain-lain. Media jejaring sosial dapat juga dimanfaatkan untuk keperluan pendidikan. Media jejaring sosial yang akan digunakan dalam keperluan penelitian ini adalah Edmodo. Penelitian ini dilakukan untuk mengetahui pengaruh positif penerapan media jejaring sosial edmodo terhadap hasil belajar fisika dasar.

Edmodo merupakan platform pembelajaran berbasis jejaring sosial yang diperuntukan untuk guru, murid sekaligus orang tua murid [2]. Edmodo sendiri dapat dikatakan sebagai program pembelajaran e-learning yang menerapkan sistem pembelajaran yang mudah, efisien, dan menyenangkan. Edmodo termasuk salah satu jaringan sosial yang cepat berkembang. Edmodo merupakan salah satu media pembelajaran online yang menghubungkan antara dosen dan mahasiswa dalam proses pembelajaran. Dimana penggunaannya dapat dilakukan kapan saja dan dimana saja.

Mengapa Edmodo dikatakan dapat membantu proses pembelajaran. Sebab edmodo terdapat fitur-fitur yang dapat digunakan untuk mengelola kelas, seperti menunjukkan informasi, memberikan tugas maupun soal yang harus dikerjakan secara online dengan batas waktu tertentu, tanya jawab antara dosen dan mahasiswa dan lain sebagainya. Tampilan yang diperlihatkan edmodo hampir sama dengan desain tampilan Facebook yang memudahkan penggunanya. Sehingga diharapkan ada pengaruh positif media jejaring sosial Edmodo terhadap hasil belajar fisika dasar.

Adapun manfaat dari Edmodo dalam pembelajaran adalah sebagai berikut :

1. Edmodo merupakan wahana komunikasi dan diskusi yang sangat efiesien untuk para guru dan murid;

2. Dengan Edmodo, siswa satu dengan siswa lainnya dapat dengan mudah 
berinteraksi dan berdiskusi dengan pantauan langsung dari gurunya;

3. Selain itu, Edmodo mempermudah komunikasi antara guru, murid sekaligus orang tua murid;

4. Sebagai sarana yang tepat untuk ujian maupun quiz;

5. Guru dapat memberikan bahan ajar seperti pertanyaan, foto, video pembelajaran kepada murid dengan mudah. Selain itu, murid juga dapat mengunduh bahan ajar tersebut;

6. Dengan adanya Edmodo, orang tua murid dapat memantau kegiatan belajar anaknya dengan mudah;

7. Mempermudah guru dalam memberikan soal dari mana saja dan kapan saja.[3]

Akan tetapi penggunaan edmodo sendiri kurang dimaksimalkan oleh praktisi pendidikan seperti guru dan dosen. Padahal edmodo sangat mudah digunakan kapan saja dan dimana saja dalam proses belajar mengajar, orang tua pun dapat mengontrol kelas anaknya dalam proses belajar mengajar. Padahal diera teknologi yang sedang berkembang ini media sosial sangat banyak sekali seperti facebook, twitter, instagram, edmodo, dan lain sebagainya. Hanya saya pemanfaatan untuk proses pembelajaran dirasa masih sangat minim.

Fisika adalah ilmu yang mempelajari benda-benda serta fenomena dan keadaan yang terkait dengan benda-benda tersebut. Untuk menggambarkan suatu fenomena yang terjadi atau dialami suatu benda, maka didefinisikan berbagai besaranbesaran fisika. Besaran-besaran fisika ini misalnya panjang, jarak, massa, waktu, gaya, kecepatan, temperatur, intensitas cahaya, dan sebagainya. Terkadang nama dari besaran-besaran fisika tadi memiliki kesamaan dengan istilah yang dipakai dalam keseharian, tetapi perlu diperhatikan bahwa besaran-besaran fisika tersebut tidak selalu memiliki pengertian yang sama dengan istilah-istilah keseharian [4]. Hasil belajar adalah suatu penilaian akhir dari proses dan pengenalan yang telah dilakukan berulang-ulang. Serta akan tersimpan dalam jangka waktu lama atau bahkan tidak akan hilang selama-lamanya karena hasil belajar turut serta dalam membentuk pribadi individu yang selalu ingin mencapai hasil yang lebih baik lagi sehingga akan merubah cara berpikir serta menghasilkan perilaku kerja yang lebih baik [5]. Sedangkan Hasil belajar fisika dasar adalah nilai akhir yang didapatkan mahasiswa setelah melakukan proses belajar fisika dasar yang mempelajari fenomena alam dan sekitarnya secara berulang-ulang.

Berdasarkan analisis permasalahan tersebut maka diperlukan suatu media jejaring sosial edmodo agar pembelajaran fisika dasar menyenangkan dan memperoleh hasil belajar fisika dasar yang memuaskan. Diharapkan penggunaan media jejaring sosial edmodo dapat memberikan pengaruh yang positif terhadap hasil belajar fisika dasar. Dimana hipotesis dalam penelitian ini adalah:

$\mathrm{H}_{0}$ : Tidak ada pengaruh positif penerapan media jejaring sosial edmodo terhadap hasil belajar fisika dasar

$\mathrm{H}_{1}$ : Ada pengaruh positif penerapan media jejaring sosial edmodo terhadap hasil belajar fisika dasar

\section{METODE}

Penelitian ini dilakukan di Universitas Indraprasta PGRI. Populasi adalah mahasiswa tingkat pertama tahun akademik 2018/2019 yang berjumlah 160 mahasiswa yang dibagi menjadi ke dalam 4 kelas paralel. Sampel yang diambil dalam penelitian ada dua kelas dengan menggunakan teknik sampel bertujuan atau purposive sample, yaitu pengambilan sampel bukan didasarkan pada strata, random, atau daerah tetapi didasarkan atas adanya tujuan tertentu [6]. 
Desain eksperimen yang digunakan adalah classical experimental design. Analisis data yang digunakan untuk desain eksperimen ini menggunakan Independent sample t-test. Uji independent sample t-test digunakan untuk menguji signifikansi beda rata-rata dua kelompok sampel, selain itu uji ini bisa juga digunakan untuk menguji pengaruh variabel independent terhadap variabel dependent. Dalam hal ini yang menjadi variabel independent yaitu media jejaring sosial edmodo dan variabel dependent yaitu hasil belajar fisika dasar.

Kriteria pengujian hipotesis

1. Jika nilai sig (2 tailed) $<0,05$ maka ada pegaruh penerapan media jejaring sosial edmodo terhadap hasil belajar fisika dasar

2. Jika nilai sig (2 tailed) $>0,05$ maka tidak ada pegaruh penerapan media jejaring sosial edmodo terhadap hasil belajar fisika dasar

\section{HASIL DAN PEMBAHASAN}

Berdasarkan hasil pengolahan data diperoleh hasil:

\begin{tabular}{|c|c|c|}
\hline & & $\begin{array}{l}\text { Hasil Belajar } \\
\text { Fisika Dasar }\end{array}$ \\
\hline \multicolumn{2}{|l|}{$\mathrm{N}$} & 80 \\
\hline \multirow[t]{2}{*}{ Normal Parameters ${ }^{\mathrm{a}}$} & Mean & 68.75 \\
\hline & $\begin{array}{l}\text { Std. } \\
\text { Deviation }\end{array}$ & 10.204 \\
\hline \multirow{3}{*}{$\begin{array}{l}\text { Most Extreme } \\
\text { Differences }\end{array}$} & Absolute & .130 \\
\hline & Positive & .118 \\
\hline & Negative & -.130 \\
\hline \multicolumn{2}{|c|}{ Kolmogorov-Smirnov Z } & 1.162 \\
\hline \multicolumn{2}{|l|}{ Asymp. Sig. (2-tailed) } & .134 \\
\hline \multicolumn{2}{|c|}{ a. Test distribution is Normal. } & \\
\hline
\end{tabular}

\begin{tabular}{|c|c|c|c|c|}
\hline & & t-test $\mathrm{f}$ & $\begin{array}{l}\text { or Equal } \\
\text { Means }\end{array}$ & lity of \\
\hline & & $\mathrm{t}$ & $\mathrm{df}$ & $\begin{array}{l}\text { Sig. (2- } \\
\text { tailed) }\end{array}$ \\
\hline $\begin{array}{l}\text { Hasil } \\
\text { Belajar }\end{array}$ & $\begin{array}{l}\text { Equal variances } \\
\text { assumed }\end{array}$ & -9.033 & 78 & .000 \\
\hline $\begin{array}{l}\text { Fisika } \\
\text { Dasar }\end{array}$ & $\begin{array}{l}\text { Equal variances } \\
\text { not assumed }\end{array}$ & -9.033 & 77.952 & .000 \\
\hline
\end{tabular}

Perhitungan menggunakan bantuan SPSS 18. Berdasarkan hasil perhitungan tabel 1 yang diperoleh terlihat bahwa nilai ratarata yang diperoleh dari 80 mahasiswa yaitu 68,75 dengan standar deviasi 10,204. Terlihat juga nilai sig pada metode Kolmogorov-Smirnov sebesar 0,134. Berdasarkan kriteria pengujian dimana $0,134>0,05$ maka dapat dikatakan bahwa sampel pada penelitian ini berdistribusi normal dan dapat digunakan untuk penelitian.

Menurut kriteria pengujian hipotesis jika nilai sig ( 2 tailed) $<0,05$ maka ada pegaruh penerapan media jejaring sosial edmodo terhadap hasil belajar fisika dasar. Berdasarkan hasil perhitungan tabel 2, terlihat nilai sig sebesar $0,00<0,05$, sehingga $\mathrm{H}_{0}$ ditolak dan $\mathrm{H}_{1}$ diterima. Dengan kata lain ada pegaruh penerapan media jejaring sosial edmodo terhadap hasil belajar fisika dasar.

Berdasarkan sintesis teori yang ada Edmodo merupakan platform pembelajaran berbasis jejaring sosial yang diperuntukan untuk guru, murid sekaligus orang tua murid. Sedangkan Hasil belajar fisika dasar adalah nilai akhir yang didapatkan mahasiswa setelah melakukan proses belajar fisika dasar yang mempelajari fenomena alam dan sekitarnya secara berulang-ulang. 
Semakin aktif dosen dan mahasiswa dalam menggunakan media jejaring sosial edmodo dalam proses pembelajaran maka akan semakin baik juga hasil belajar fisika dasarnya. Sebaliknya jika dosen dan mahasiswa kurang aktif menggunakan media jejaring sosial edmodo dan hanya menggunakan metode konvensional dalam proses pembelajaran maka tidak dapat dipungkiri hasil belajar fisika dasarnya kurang memuaskan. Oleh sebab itu dosen diharapkan memanfaatkan dan menggunakan media jejaring sosial edmodo sebagai salah satu metode pembelajaran yang aktif bagi mahasiswa.

\section{SIMPULAN}

Berdasarkan perhitungan SPSS 18, terlihat nilai sig sebesar $0,00<0,05$ sehingga $\mathrm{H}_{0}$ ditolak dan $\mathrm{H}_{1}$ diterima. Dengan kata lain ada pengaruh positif penerapan media jejaring sosial edmodo terhadap hasil belajar fisika dasar. Dari hasil penelitian dan pembahasan di atas, maka dapat disimpulkan bahwa ada pengaruh positif penerapan media jejaring sosial edmodo terhadap hasil belajar fisika dasar. Sehingga dapat dijadikan sebagai acuan bagi dosen yang lainnya khususnya peneliti bahwa penerapan media jejaring sosial Edmodo dapat meningkatkan hasil belajar fisika dasar.

\section{DAFTAR PUSTAKA}

[1] Asmuni, Wiwin SH. "Pengaruh Penggunaan Media Jejaring Sosial Edmodo Terhadap Partisipasi Mahasiswa dalam Diskusi Kelas pada Materi Ajar Teoritis dan Praktis". Prosiding Seminar Nasional Hasil Penelitian Pendidikan dan Pembelajaran. STKIP PGRI. Jombang, 2015.

[2] M Zakaria. "Tentang Edmodo: Pengertian, Manfaat, dan Fiturfiturnya yang Wajib Anda Ketahui”. 2018. [Online]. Tersedia: https://www.nesabamedia.com/penge rtian-manfaat-dan-fituredmodo/\#comments

[Diakses 14 Oktober 2018]

[3] Mirza S. "Fisika Dasar". [Online]. Tersedia:

https://cobaberbagi.files.wordpress.c om/2010/01/fisika-dasar.pdf [Diakses 14 Oktober 2018]. 2007.

[4] Fadlin. "Hubungan Antara Motivasi Berprestasi Dengan Hasil Belajar Fisika Peserta Didik Kelas XI SMA di Kota Bima”. Eduscience, vol. 2, no. 1, pp. 1-7. 2016.

[5] Hamid Darmadi. Metode Penelitian Pendidikan. Bandung: Alfabeta; 2011. 